\title{
Regioselective Syntheses of 3-Benzyl-Substituted 7H-Thiazolo[3,2-a]pyrimidine-7-ones through Palladium-Catalyzed Heteroannulation of Acetylenic Compounds
}

\author{
Mohammad Bakherad and Farzaneh Gholipoor \\ School of Chemistry, Shahrood University of Technology, Shahrood 3619995161, Iran \\ Correspondence should be addressed to Mohammad Bakherad, m.bakherad@yahoo.com
}

Received 8 June 2012; Revised 2 August 2012; Accepted 5 August 2012

Academic Editor: Dipakranjan Mal

Copyright ( 92012 M. Bakherad and F. Gholipoor. This is an open access article distributed under the Creative Commons Attribution License, which permits unrestricted use, distribution, and reproduction in any medium, provided the original work is properly cited.

An efficient synthesis of 3-benzyl-substituted 7H-thiazolo[3,2-a]pyrimine-7-ones in acetonitrile is accomplished via Pd- and Cucatalyzed reaction of 2-mercaptopropargylpyrimidone with various aryl iodides in the presence of triethylamine as the base.

\section{Introduction}

The Sonogashira reaction is one of the most widely used C$\mathrm{C}$ bond formation ones $[1,2]$. It provides an efficient route to aryl alkynes, which are interesting intermediates for the preparation of a variety of target compounds with applications ranging from natural products [3-7] and pharmaceuticals [8] to molecular organic materials [9]. Due to the utility of the products, development of new catalyst systems has received considerable attention. Palladium-catalyzed reactions have been immensely practical for both carboannulation $[10,11]$ and heteroannulation [12-16] processes.

Thiazole and pyrimidine nuclei are the active core of various bioactive molecules. In general, heterocycles encompassing a pyrimidine unit have found applications in a wide spectrum of biological and therapeutic areas $[17,18]$. Thus, the heterocyclic system resulting from annulation of a pyrimidine ring on the biologically versatile thiazole nucleus is an attractive scaffold to be utilized for exploiting chemical diversity.

Continuing our efforts directed towards the straightforward preparation of biologically active target molecules through Sonogashira coupling reactions [1922], we performed the synthesis of new derivatives of thiazolo[3,2-a]pyrimidones via $\mathrm{Pd}$ - and $\mathrm{Cu}$-catalyzed Sonogashira coupling reaction.

\section{Results and Discussion}

In this communication, we wish to report that treatment of 2-thiouracil 1 with propargyl bromide in $\mathrm{MeONa} / \mathrm{MeOH}$ affords 2-propargylmercaptouracil 2 in a good yield. The ${ }^{1} \mathrm{H}$ NMR spectrum of 2 showed a $\mathrm{CH}$ proton at $2.17 \mathrm{ppm}$, $\mathrm{CH}_{2}$ protons at $3.92 \mathrm{ppm}$, and a single resonance for the $\mathrm{NH}$ group at $13.05 \mathrm{ppm}$ that disappeared on deuteration (as shown in Scheme 1).

Reaction of compound $\mathbf{2}$ with various aryl iodides, $\mathbf{3 a}-\mathbf{f}$, in acetonitrile at room temperature led only to the formation of 3-benzyl-substituted 7H-thiazolo[3, 2-a] pyrimidine7-ones 4. The reactions were carried out under an argon atmosphere, and solvent was degassed prior to use. Presence of electron withdrawing groups such as $\mathrm{NO}_{2}, \mathrm{Cl}$, and $\mathrm{COMe}$ on the aryl iodide seems to be essential. When iodobenzene was used as the aryl iodide, Sonogashira coupling could not be achieved. The results were tabulated in Table 1 .

The following steps can be postulated for the mechanism of formation of either thiazolo[3,2-a]pyrimidine-7-ones 4 or thiazolo[3,2-a]pyrimidine-5-ones 5 (Scheme 2): (a) formation of ArPdI (II) through oxidative addition of $\mathrm{Pd}(0)$ (I) to ArI [23]; (b) transmetallation with the $\mathrm{Cu}$ salt of the alkyne (III) to generate the alkynyl palladium complex (IV); (c) reductive elimination results in the extrusion of $\operatorname{Pd}(0)$ to yield the substituted alkyne (V); (d) finally, nucleophilic 


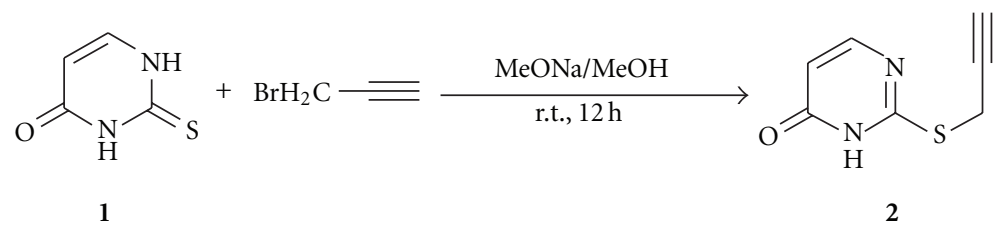

Scheme 1

TABLE 1: Melting points and yields of 3-aryl-substituted 7H-thiazolo[3,2-a]pyrimidine-7-ones.

Entry

$4 c \quad 250-252$

\footnotetext{
${ }^{a}$ Reaction reagents and conditions: 2 (1.3 mmol), 2 a-f $(1 \mathrm{mmol}), \mathrm{Et}_{3} \mathrm{~N}(2 \mathrm{mmol}), \mathrm{Pd}(\mathrm{PPh}){ }_{3} \mathrm{Cl}_{2}(0.03 \mathrm{mmol}), \mathrm{CuI}(0.06 \mathrm{mmol}), \mathrm{and} \mathrm{CH}{ }_{3} \mathrm{CN}(5 \mathrm{~mL}), \mathrm{room}$ temperature, $24 \mathrm{~h}$.
}

attack of the nitrogen on the triple-bond intermediates (V) catalyzed by CuI led to product $\mathbf{4}$ or 5 .

Structures $\mathbf{4}$ and $\mathbf{5}$ were characterized by comparing their spectra with those for the well-established compounds 6a [24], 6b [25], and 7 [25] (Scheme 3). The IR spectra for $\mathbf{4}$ or $\mathbf{5}$ were quite similar to that for $\mathbf{6}$. Therefore, we can conclude that the one-pot condensation, cyclization, and isomerization of acetylenic compounds regioselectively afford 4.

The ${ }^{1} \mathrm{H}$ NMR spectrum of $\mathbf{4 a}$ exhibited an aromatic proton at $6.70 \mathrm{ppm}$, which was characteristic of a fused thiazole ring. The other four aromatic protons appeared at $8.10-8.40 \mathrm{ppm}$. In the aliphatic region, the singlet at $4.30 \mathrm{ppm}$ was due to the benzylic protons. 


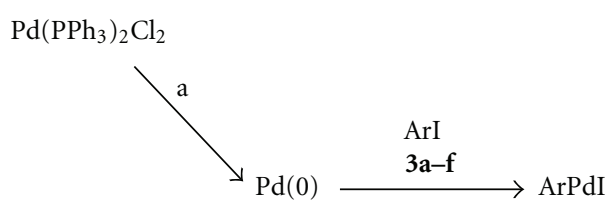

(I)

(II)<smiles>C#CCSc1nccc(=O)[nH]1</smiles>

2

(III)

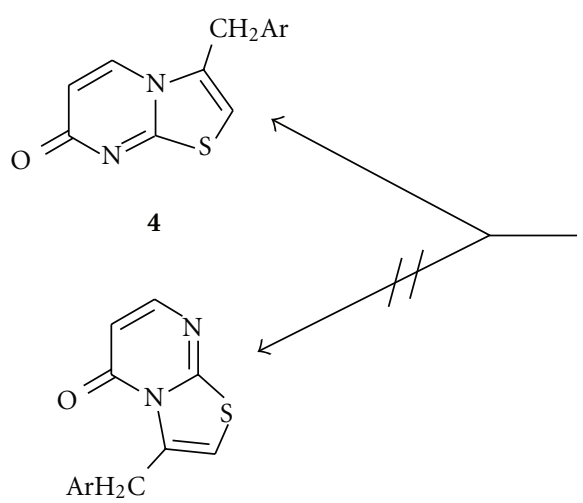

(V)

5

Scheme 2: Proposed mechanism for the formation of either 3-aryl-substituted 7H-thiazolo[3,2-a]pyrimidine-7-ones 4 or 3-aryl-substituted $5 \mathrm{H}$-thiazolo[3,2-a] pyrimidine-5-ones 5 at room temperature. Reagents and conditions: (a) reduction of $\mathrm{Pd}(\mathrm{II})$ to $\mathrm{Pd}(0)$ with alkyne and Et3N; (b) CuI, Et3N; (c) nucleophilic attack on the triple band (V) catalyzed by CuI, Et3N to generate the product 4 or 5.

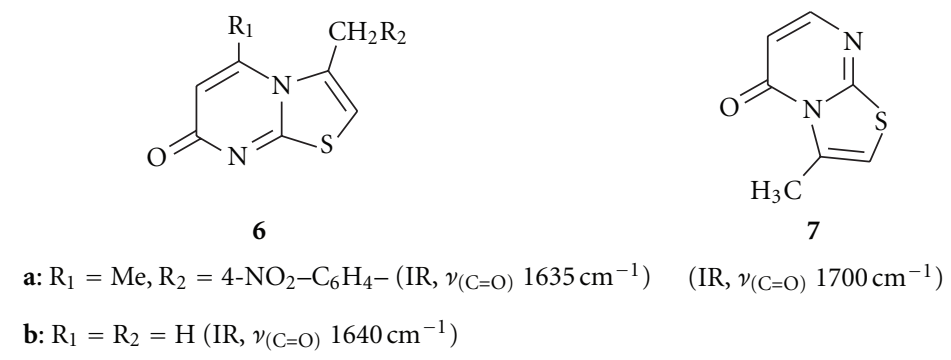

Scheme 3

In conclusion, we have described a palladium-catalyzed, one-pot reaction for the regioselective syntheses of 3aryl-substituted $7 \mathrm{H}$-thiazolo[3,2-a]pyrimidine-7-ones from readily available starting materials in moderate-to-good yields.

\section{Experimental}

Melting points were uncorrected. The ${ }^{1} \mathrm{H}$ NMR spectra were recorded at $400 \mathrm{MHz}$, and the ${ }^{13} \mathrm{C}$ NMR spectra were recorded at $100 \mathrm{MHz}$ in DMSO- $d_{6}$. The J-coupling constants are reported in $\mathrm{Hz}$.

3.1. Synthesis of 2-Propargylmercaptouracil 2. A mixture of sodium $(1.2 \mathrm{mmol})$ and 2 -thiouracile $\mathbf{1}(1 \mathrm{mmol})$ was stirred in methanol $(5 \mathrm{~mL})$. Propargyl bromide $(1.2 \mathrm{mmol})$ was then added, and the mixture was stirred at room temperature for $24 \mathrm{~h}$. The solid substance formed was filtered, washed with water, and recrystallized from water to afford the title compound. 
Yield, 78\%; m.p., $152-153^{\circ} \mathrm{C}$; IR (KBr, $\left.\nu_{\max } \mathrm{cm}^{-1}\right)$ : 3200, 2100, 1645. ${ }^{1} \mathrm{H}$ NMR (400 MHz, DMSO- $\left.d_{6} \delta \mathrm{ppm}\right): 2.10(\mathrm{~s}$, $1 \mathrm{H}, \mathrm{CH}), 3.90\left(\mathrm{~s}, 2 \mathrm{H}, \mathrm{CH}_{2}\right), 6.10(\mathrm{~d}, J=6.4 \mathrm{~Hz}, 1 \mathrm{H}, \mathrm{CH}$ of pyrimidine), 7.80 (d, $J=6.4 \mathrm{~Hz}, 1 \mathrm{H}, \mathrm{CH}$ of pyrimidine), 13.05 (s, 1H, NH).

3.2. Syntheses of 3-Aryl-Substituted 7H-Thiazolo[3,2-a]pyrimidine-7-ones $\mathbf{4 a}-\boldsymbol{f}$. A mixture of aryl iodide ( $1 \mathrm{mmol})$, $\mathrm{PdCl}_{2}\left(\mathrm{PPh}_{3}\right)_{2} \quad(0.03 \mathrm{mmol})$, Cul $(0.06 \mathrm{mmol})$, and triethylamine $(2.0 \mathrm{mmol})$ was stirred in acetonitrile $(5 \mathrm{~mL})$ under an argon atmosphere. 2-Propargylmercaptouracil 2 $(1.3 \mathrm{mmol})$ was then added, and the mixture was stirred at room temperature for $12 \mathrm{~h}$. The solid substance formed was filtered, washed with water, and recrystallized from acetonitrile (Table 1).

3.2.1. 3-(2-Nitrobenzyl)-7H-thiazolo[3,2-a]pyrimidine-7-one 4a. IR $\left(\mathrm{KBr}, \nu_{\max } \mathrm{cm}^{-1}\right): 1645,1510,1345 .{ }^{1} \mathrm{H}$ NMR (400 MHz, DMSO- $\left.d_{6} \delta \mathrm{ppm}\right): 4.30\left(\mathrm{~s}, 2 \mathrm{H}, \mathrm{CH}_{2}\right), 6.20(\mathrm{~d}, J=$ $8.0 \mathrm{~Hz}, 1 \mathrm{H}, \mathrm{CH}$ of pyrimidine), $6.70(\mathrm{~s}, 1 \mathrm{H}, \mathrm{CH}$ of thiazole), $7.84(\mathrm{~d}, J=8.0 \mathrm{~Hz}, 1 \mathrm{H}, \mathrm{CH}$ of pyrimidine $), 8.10-8.40(\mathrm{~m}$, 4H, ArH); HRMS (ESI): 287.010.

3.2.2. 3-(3-Nitrobenzyl)-7H-thiazolo[3,2-a]pyrimidine-7-one 4b. IR $\left(\mathrm{KBr}, \nu_{\max } \mathrm{cm}^{-1}\right): 1645,1520,1330 .{ }^{1} \mathrm{H}$ NMR (400 MHz, DMSO- $\left.d_{6} \delta \mathrm{ppm}\right): 4.36\left(\mathrm{~s}, 2 \mathrm{H}, \mathrm{CH}_{2}\right), 5.72(\mathrm{~d}, J=$ $8.0 \mathrm{~Hz}, 1 \mathrm{H}, \mathrm{CH}$ of pyrimidine), $6.55(\mathrm{~s}, 1 \mathrm{H}, \mathrm{CH}$ of thiazole), $7.20(\mathrm{~d}, J=8.0 \mathrm{~Hz}, 1 \mathrm{H}, \mathrm{CH}$ of pyrimidine), 7.80-8.10 (m, 4H, ArH); HRMS (ESI): 287.053.

3.2.3. 3-(4-Nitrobenzyl)-7H-thiazolo[3,2-a]pyrimidine-7-one 4c. IR $\left(\mathrm{KBr}, \nu_{\max } \mathrm{cm}^{-1}\right): 1645,1510,1345 .{ }^{1} \mathrm{H}$ NMR (400 MHz, DMSO- $\left.d_{6} \delta \mathrm{ppm}\right): 4.07\left(\mathrm{~s}, 2 \mathrm{H}, \mathrm{CH}_{2}\right), 6.30$ (d, $J=$ $8.0 \mathrm{~Hz}, 1 \mathrm{H}, \mathrm{CH}$ of pyrimidine $), 6.35(\mathrm{~s}, 1 \mathrm{H}, \mathrm{CH}$ of thiazole), 7.45 (dd, $J=8.0,1.6 \mathrm{~Hz}, 2 \mathrm{H}, \mathrm{ArH}), 7.53$ (d, $J=8.0 \mathrm{~Hz}, 1 \mathrm{H}$, CH of pyrimidine), 8.2 (dd, $J=8.0,1.6 \mathrm{~Hz}, 2 \mathrm{H}, \mathrm{ArH}$ ); HRMS (ESI): 287.018 .

3.2.4. 3-(4-Chloro-2-nitrobenzyl)-7H-thiazolo[3,2-a]pyrimidine-7-one $4 d$. IR (KBr, $\left.\nu_{\max } \mathrm{cm}^{-1}\right): 1640,1530,1340 ;{ }^{1} \mathrm{H}$ NMR (400 MHz, DMSO- $d_{6} \delta$ ppm): 4.27 (s, 2H, $\mathrm{CH}_{2}$ ), 6.20 (s, $1 \mathrm{H}, \mathrm{CH}$ of thiazole), $6.34(\mathrm{~d}, J=8.0 \mathrm{~Hz}, 1 \mathrm{H}, \mathrm{CH}$ of pyrimidine), 7.58 (dd, $J=8.0,2.0 \mathrm{~Hz}, 1 \mathrm{H}, \mathrm{ArH}), 7.65$ (d, $J=$ $8.0 \mathrm{~Hz}, 2 \mathrm{H}, \mathrm{CH}$ of pyrimidine and $\mathrm{ArH}), 8.10(\mathrm{~d}, J=2.0 \mathrm{~Hz}$, 1H, ArH); HRMS (ESI): 320.966.

3.2.5. 3-(2-Methyl-4-nitrobenzyl)-7H-thiazolo[3,2-a]pyrimidine-7-one $4 \boldsymbol{e}$. IR $\left(\mathrm{KBr}, \nu_{\max } \mathrm{cm}^{-1}\right): 1640,1520,1345 ;{ }^{1} \mathrm{H}$ NMR (400 MHz, DMSO- $d_{6} \delta$ ppm): $2.40\left(\mathrm{~s}, 3 \mathrm{H}, \mathrm{CH}_{3}\right), 3.97$ $\left(\mathrm{s}, 2 \mathrm{H}, \mathrm{CH}_{2}\right), 6.10(\mathrm{~s}, 1 \mathrm{H}, \mathrm{CH}$ of thiazole $), 6.35(\mathrm{~d}, J=$ $8.0 \mathrm{~Hz}, 1 \mathrm{H}, \mathrm{CH}$ of pyrimidine $), 7.60(\mathrm{~d}, J=8.0,1 \mathrm{H}, \mathrm{CH}$ of pyrimidine), 7.95-8.20 (m, 3H, ArH); HRMS (ESI): 301.352.

3.2.6. 3-(4-Acetylbenzyl)-7H-thiazolo[3,2-a]pyrimidine-7one 4 f. IR ( $\left.\mathrm{KBr}, v_{\max } \mathrm{cm}^{-1}\right)$ : 1680,$1645 ;{ }^{1} \mathrm{H} \mathrm{NMR}(400 \mathrm{MHz}$, DMSO- $\left.d_{6} \delta \mathrm{ppm}\right): 2.64\left(\mathrm{~s}, 3 \mathrm{H}, \mathrm{CH}_{3}\right), 4.10\left(\mathrm{~s}, 2 \mathrm{H}, \mathrm{CH}_{2}\right), 6.35$ (d, $J=8.0 \mathrm{~Hz}, 1 \mathrm{H}, \mathrm{CH}$ of pyrimidine), 6.45 (s, $1 \mathrm{H}, \mathrm{CH}$ of thiazole), 7.36 (d, $J=8.0 \mathrm{~Hz}, 2 \mathrm{H}, \operatorname{ArH}), 7.62(\mathrm{~d}, J=8.0,1 \mathrm{H}$, $\mathrm{CH}$ of pyrimidine), $8.02(\mathrm{~d}, J=8.0 \mathrm{~Hz}, 2 \mathrm{H}, \mathrm{ArH})$; HRMS (ESI): 284.302.

\section{Acknowledgment}

The authors would like to thank the Research Council of Shahrood University of Technology for the support of this work.

\section{References}

[1] K. Sonogashira, "Development of $\mathrm{Pd}-\mathrm{Cu}$ catalyzed crosscoupling of terminal acetylenes with $\mathrm{sp}^{2}$-carbon halides," Journal of Organometallic Chemistry, vol. 653, no. 1-2, pp. 4649, 2002.

[2] R. Chinchilla and C. Najera, "The Sonogashira reaction: a booming methodology in synthetic organic chemistry," Chemical Reviews, vol. 107, no. 3, pp. 874-922, 2007.

[3] M. Toyota, C. Komori, and M. Ihara, "A concise formal total synthesis of mappicine and nothapodytine B via an intramolecular hetero Diels-Alder reaction," The Journal of Organic Chemistry, vol. 65, no. 21, pp. 7110-7113, 2000.

[4] F. Yoshimura, S. Kawata, and M. Hirama, "Synthetic study of kedarcidin chromophore: atropselective construction of the ansamacrolide," Tetrahedron Letters, vol. 40, no. 47, pp. 82818285, 1999.

[5] M. W. Miller and C. R. Johnson, "Sonogashira Coupling of 2iodo-2-cycloalkenones: synthesis of (+)- and (-)-harveynone and (-)-tricholomenyn A," The Journal of Organic Chemistry, vol. 62, no. 6, pp. 1582-1585, 1997.

[6] A. Sakai, T. Aoyama, and T. Shioiri, "Total synthesis of vibsanol, a benzofuran-type lignan," Tetrahedron Letters, vol. 40, no. 22, pp. 4211-4214, 1999.

[7] A. E. Graham, D. McKerrecher, D. H. Davies, and R. J. K. Taylor, "Sonogashira coupling reactions of highly oxygenated vinyl halides: the first synthesis of harveynone and epiharveynone," Tetrahedron Letters, vol. 37, no. 41, pp. 7445$7448,1996$.

[8] J. W. Grissom, G. U. Gunawardena, D. Klingberg, and D. Huang, "The chemistry of enediynes, enyne allenes and related compounds," Tetrahedron, vol. 52, no. 19, pp. 6453-6518, 1996.

[9] R. Wu, J. S. Schumm, D. L. Pearson, and J. M. Tour, "Convergent synthetic routes to orthogonally fused conjugated oligomers directed toward molecular scale electronic device applications," The Journal of Organic Chemistry, vol. 61, no. 20, pp. 6906-6921, 1996.

[10] N. C. Ihle and C. H. Heathcock, "Palladium-catalyzed intramolecular alkyne-carbon monoxide-alkene insertion cascade for synthesis of .alpha.-methylenecyclopentenones," The Journal of Organic Chemistry, vol. 58, no. 3, pp. 560-563, 1993.

[11] R. C. Larock, M. J. Doty, and S. Cacchi, "Synthesis of indenones via palladium-catalyzed annulation of internal alkynes," The Journal of Organic Chemistry, vol. 58, no. 17, pp. 4579-4583, 1993.

[12] A. Arcadi, S. Cacchi, and F. Marinelli, "Palladium-catalysed coupling of aryl and vinyl triflates or halides with 2ethynylaniline: an efficient route to functionalized 2substituted indoles," Tetrahedron Letters, vol. 30, no. 19, pp. 2581-2584, 1989.

[13] K. R. Roesch and R. C. Larock, "Synthesis of isoquinolines and pyridines via palladium-catalyzed iminoannulation of internal 
acetylenes," The Journal of Organic Chemistry, vol. 63, no. 16, pp. 5306-5307, 1998.

[14] R. C. Larock, E. K. Yum, and M. D. Refvik, "Synthesis of 2,3disubstituted indoles via palladium-catalyzed annulation of internal alkynes," The Journal of Organic Chemistry, vol. 63, no. 22, pp. 7652-7662, 1998.

[15] R. Larock and X. Can, "Palladium-catalyzed cross-coupling of 2,5-cyclohexadienyl-substituted aryl or vinylic iodides and carbon or heteroatom nucleophiles," The Journal of Organic Chemistry, vol. 64, no. 6, pp. 1875-1887, 1999.

[16] F. Alonso, I. P. Belestkaya, and M. Yus, "Transition-metalcatalyzed addition of heteroatom-hydrogen bonds to alkynes," Chemical Reviews, vol. 104, no. 6, pp. 3079-3159, 2004.

[17] K. Senga, T. Novinson, H. R. Wilson, and R. K. Robins, "Synthesis and antischistosomal activity of certain pyrazolo[1,5a]pyrimidines," Journal of Medicinal Chemistry, vol. 24, no. 5, pp. 610-613, 1981.

[18] J. L. Bernier, J. P. Henichart, V. Warin, and F. Baert, "Synthesis and structure-activity relationship of a pyrimido[4,5d]pyrimidine derivative with antidepressant activity," Journal of Pharmaceutical Sciences, vol. 69, no. 11, pp. 1343-1345, 1980.

[19] M. Bakherad, H. Nasr-Isfahani, A. Keivanloo, and N. Doostmohammadi, "Pd-Cu catalyzed heterocyclization during Sonogashira coupling: synthesis of 2-benzylimidazo[1,2a]pyridine," Tetrahedron Letters, vol. 49, no. 23, pp. 3819$3822,2008$.

[20] M. Bakherad, H. Nasr-Isfahani, A. Keivanloo, and G. Sang, "Synthesis of 2-benzylimidazo[2,1-b][1,3]benzothiazoles through palladium-catalyzed heteroannulation of acetylenic compounds," Tetrahedron Letters, vol. 49, no. 43, pp. 61886191, 2008.

[21] T. A. Kamali, M. Bakherad, M. Nasrollahzadeh, S. Farhangi, and D. Habibi, "Synthesis of 6-substituted imidazo[2,1b]thiazoles via $\mathrm{Pd} / \mathrm{Cu}$-mediated Sonogashira coupling in water," Tetrahedron Letters, vol. 50, no. 39, pp. 5459-5462, 2009.

[22] M. Bakherad, A. Keivanloo, Z. Kalantar, and S. Jajarmi, "Pd/Ccatalyzed heterocyclization during copper-free Sonogashira coupling: synthesis of 2-benzylimidazo[1,2-a]pyrimidines in water," Tetrahedron Letters, vol. 52, no. 2, pp. 228-230, 2011.

[23] K. Sonogashira, Y. Tohda, and N. Hagihara, "A convenient synthesis of acetylenes: catalytic substitutions of acetylenic hydrogen with bromoalkenes, iodoarenes and bromopyridines," Tetrahedron Letters, vol. 16, no. 50, pp. 4467-4470, 1975.

[24] M. M. Heravi, A. Kivanloo, M. Rahimizadeh, M. Bakavoli, M. Ghassemzadeh, and B. Neumüller, "Regioselective synthesis of 3-benzylthiazolo[3,2-a]pyrimidones and 3-benzylthiazolo[3,2-c]pyrimidones through palladium-catalyzed heteroannulation of acetylenic compounds," Phosphorus, Sulfur and Silicon and the Related Elements, vol. 180, no. 11, pp. 24072417, 2005.

[25] H. F. Andrew and C. K. Bradsher, "A new synthesis of thiazolo[3,2-a] pyrimidinones," Journal of Heterocyclic Chemistry, vol. 24, no. 4, pp. 577-581, 1967. 


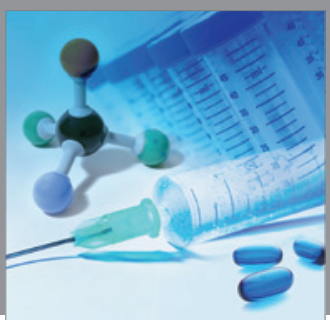

International Journal of

Medicinal Chemistry

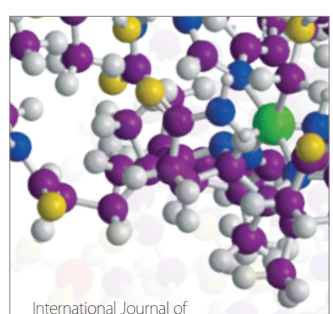

Carbohydrate Chemistry

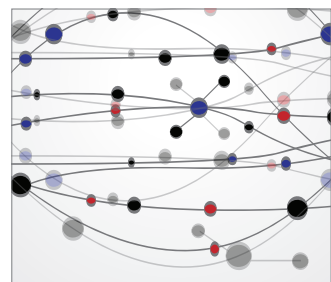

The Scientific World Journal
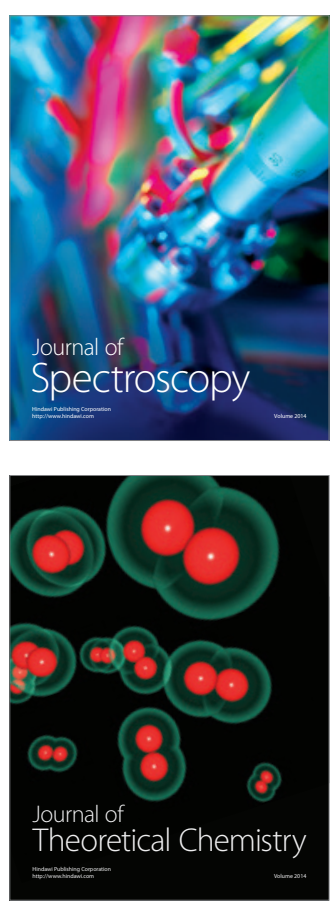
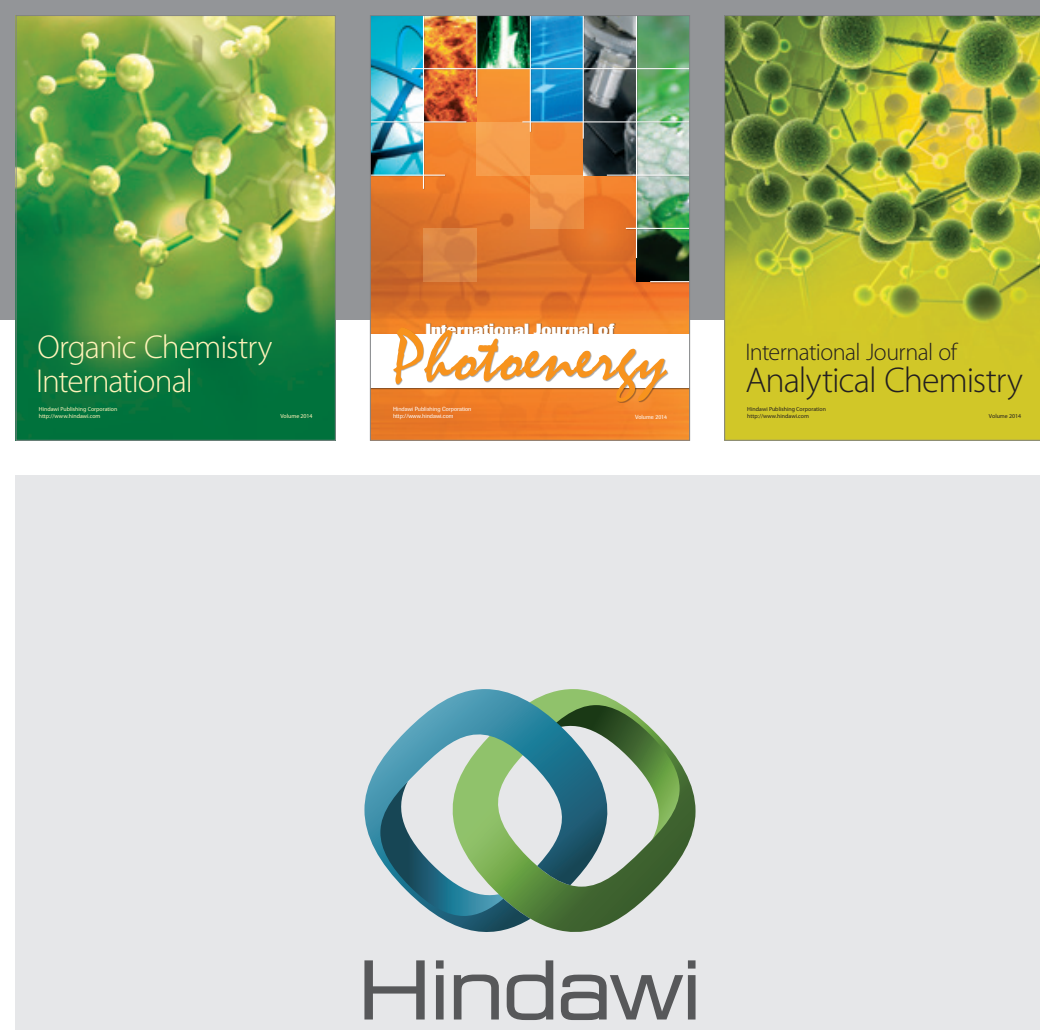

Submit your manuscripts at

http://www.hindawi.com
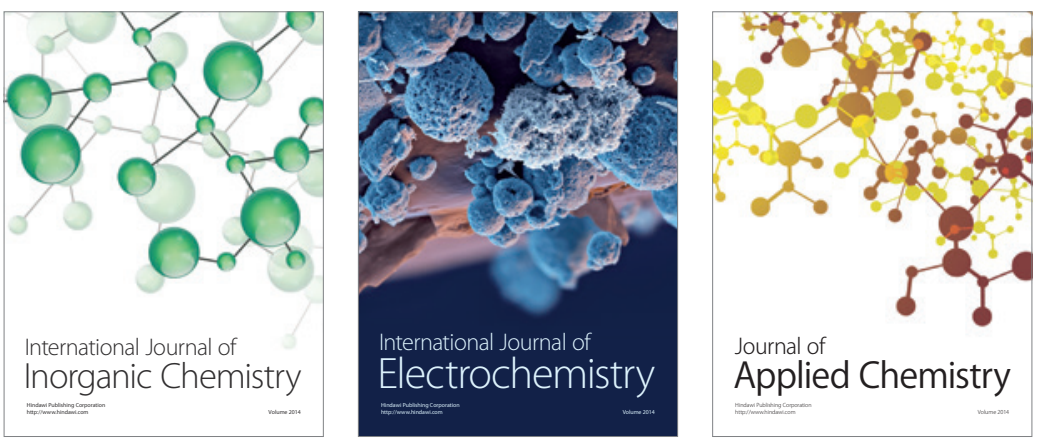

Journal of

Applied Chemistry
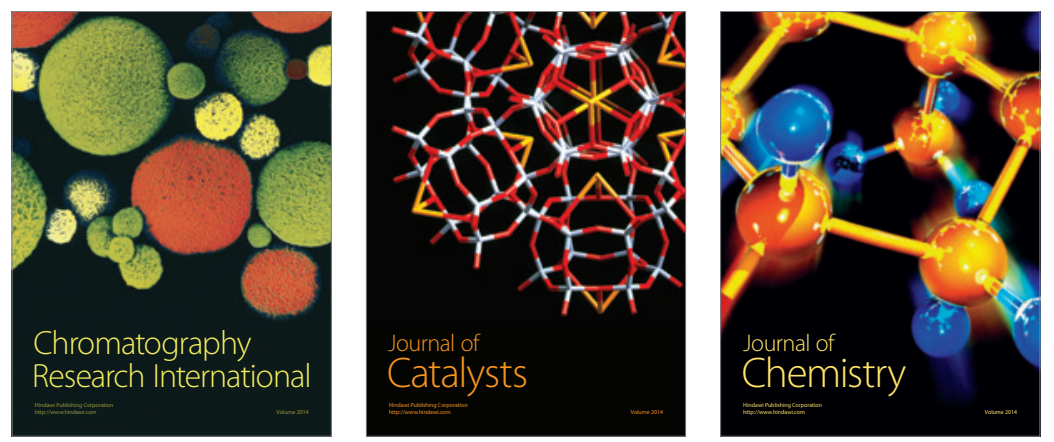
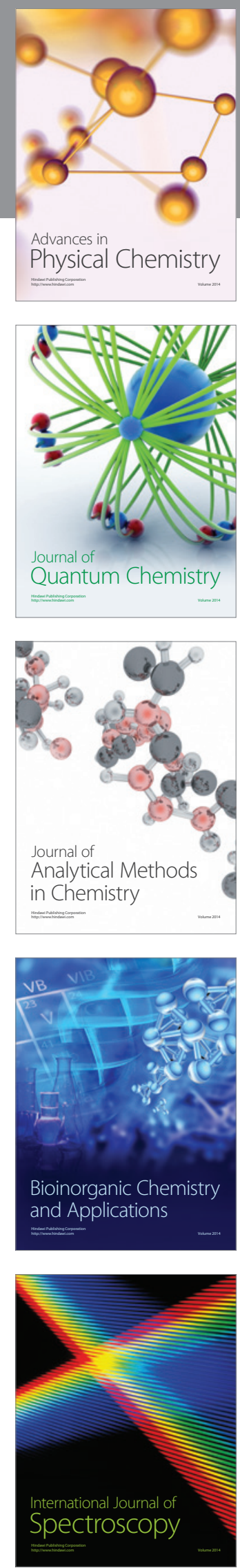